\title{
COMPARATIVE STUDY ON CONVENTIONAL AND SIMPLIFIED ELASTIC ANALYSIS OF RECTANGULAR COMBINED FOOTING
}

\author{
Bhogade Vivek ${ }^{1}$, Arkal L. $S^{2}$, Bandgar R. $V^{3}$, Kalekhan F. A.S \\ ${ }^{1}$ Assistant Professor, Department of Civil Engineering, A. G. Patil Institute of Technology, Solapur, MH, India \\ ${ }^{2} U G$ Student, Department of Civil Engineering, A. G. Patil Institute of Technology, Solapur, MH, India \\ ${ }^{3} U G$ Student, Department of Civil Engineering, A. G. Patil Institute of Technology, Solapur, MH, India \\ ${ }^{4} U G$ Student, Department of Civil Engineering, A. G. Patil Institute of Technology, Solapur, MH, India
}

\begin{abstract}
As we know the foundation is the most important member of the building and a precise analysis of footing will results in more safe and economic design. In the present study combined rectangular footing loaded with both Axial force and Moment on both columns is analyzed using Rigid (conventional) Method and the same footing is also analyzed by Finite Element and Winkler Model Approach and the results of both analysis is compared. The results of an analysis typically include support reactions, Bending and shear stresses and displacements. The Winkler Model Method is sometimes also called as Simplified Elastic Approach. Further the Computer program is written in MATLab to solve the problem and parametric study is also carried out for various values of Number of Element, Modulus of Subgrade reaction $\left(K_{f}\right)$.
\end{abstract}

Keywords: Combined Rectangular Footing, Finite Element Method, Simplified Elastic Approach

\section{INTRODUCTION}

Foundation is a structural member, made of brick work, masonry or concrete a structure which carries the entire load from superstructure and it will distribute the load on soil bellow it. The strength, stability \& support of structure are fully dependent on foundation. If some parts of superstructure fails, then repairs, modifications, additions \& alterations are possible to save the structure, but in case of foundation failure it is much difficult and very costly.

\subsection{Types of Foundation}

"Foundation" is the main part of a building which is broadly classified into two main categories Shallow foundation and Deep foundation

Depending upon the nature of soil below foundation, site condition, type and amount of loading, type of super-structure we have to choose appropriate type of foundation.

Combined footing is one in which a footing supports a line of two or more columns.

A combined footing may have either rectangular or trapezoidal shape or be a series of pads connected by narrow rigid beams called a strap footing.

\subsection{Analysis of Footing}

To get safe and economic sizes of footing we have to analyses the footing accurately. Structural analysis comprises the set of physical laws and mathematics required to study and predicts the behavior of structures. To perform an analysis a structural engineer must determine such information as structural loads, geometry, support conditions, and materials properties.

The results of such an analysis typically include support reactions, Bending and shear stresses and displacements. This information is then compared to criteria that indicate the conditions of failure.

There are four types of analysis is used for combined footing:

* Rigid Analysis

* Elastic Analysis

* Simplified Elastic Approach

* Elasto plastic Approch

Simplified Elastic Approach: In this type of analysis the soil is replaced by Independent Elastic Spring whose stiffness can be approximated by using Modulus of subgrade reaction, Base area and Depth of Foundation. It is also called as Winkler Model.

As mentioned previously combined footing can be analysed using rigid, elastic and simplified elastic method. The present study focuses on rigid and simplified elastic analysis (using Winkler model) of rectangular combined footing. 
The objective of this study is to obtain displacement, base pressure shear force and bending moment along the length of the footing. Further a Comparison will be carried out with Rigid (conventional) Analysis.

\subsection{Beams on Elastic Foundation}

When flexural rigidity of footing is taken into account, a solution based on a concept on beam on elastic foundation is used. In this concept the assumption is made that the soil bed below is made-up of Independent springs (Winkler, 1867).

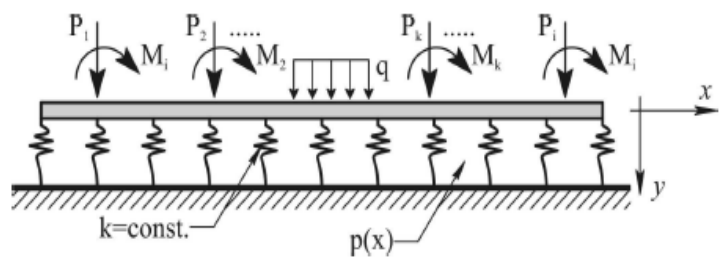

Fig -1: Winkler's Concept

The basic differential equation of Beam on Elastic Foundation is

$$
E I \frac{d^{4} y}{d x^{4}}=q_{n} \cdot b=K_{f} \cdot b \cdot y
$$

Where, $\mathrm{E}=$ modulus of elasticity of beam, $\mathrm{I}=$ moment of inertia of beam section

$\mathrm{K}_{\mathrm{f}}=$ modulus of sub-grade reaction of footing

\subsection{Finite Element Method}

Finite element Analysis is computerized method of analysis, in which a programmer writes computer code for solving the problem

In FE analysis following three steps or phase are Important
1) Pre Processing
2) Processing
3) Post Processing

Pre Processing: In this Phase the whole geometry of structure is divided into a number of small parts or elements and these elements are connected by points called as "nodes". In the present study of analysis of rectangular combined footing Beam element is used.

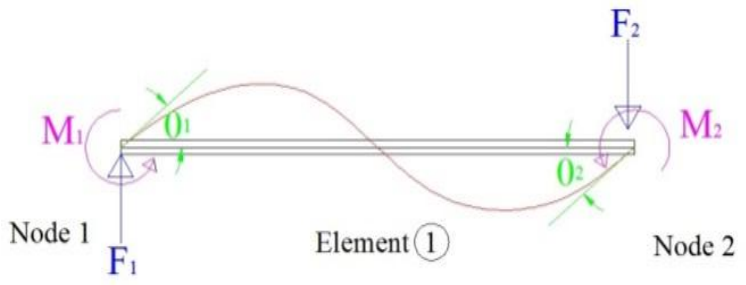

Fig -2: Beam Element

$$
k=\frac{E \times I}{L^{3}}\left[\begin{array}{cccc}
12 & 6 L & -12 & 6 L \\
6 L & 4 L^{2} & -6 L & 2 L^{2} \\
-12 & -6 L & -12 & 6 L \\
6 L & 2 L^{2} & 6 L & 4 L^{2}
\end{array}\right]
$$

Fig -3: Beam Element Stiffness matrix

$$
F=\left\{\begin{array}{c}
F_{1} \\
M_{1} \\
F_{2} \\
M_{2}
\end{array}\right\}
$$

Fig -4: Beam Element Vector matrix

Analysis or Processing: the finite element program written to construct and solve linear or non-linear equations itself. The deformations in beam element are in the form of rotation and deflection, which are occurred at the nodes. These deformations can be determined by a linear or non-linear algebraic equitation's which is constructed and solved by finite element computer code itself.

In the analysis for each Beam element discrete stiffness matrix is calculated which is normally recognized as Local stiffness matrix. Then this local stiffness matrix is combined together to form the Global stiffness matrix which is used for the analysis.

As we know, $\quad K_{i j} \times u_{j}=F_{i}$

By knowing the force applied at nodes and global stiffness matrix we can determine displacement at nodes.

Post Processing: The output of Finite element analysis or computer code is displacement and rotation at nodal point is further processed to obtain the Shear Force and Bending Moment at various nodal points.

\section{FORMULATION OF FINITE ELEMENT METHOD FOR COMBINED FOOTING}

In FEM as discussed above, the whole structure is divided and represented in Number of Elements and Nodes. In present Study for analysis of combined footing finite beam element is 
used. The property of combined footing such as width of combined footing, depth of combined footing and material property of combined footing is applied to finite beam element similarly the length of beam element is depend on length of footing and Number of beam element.

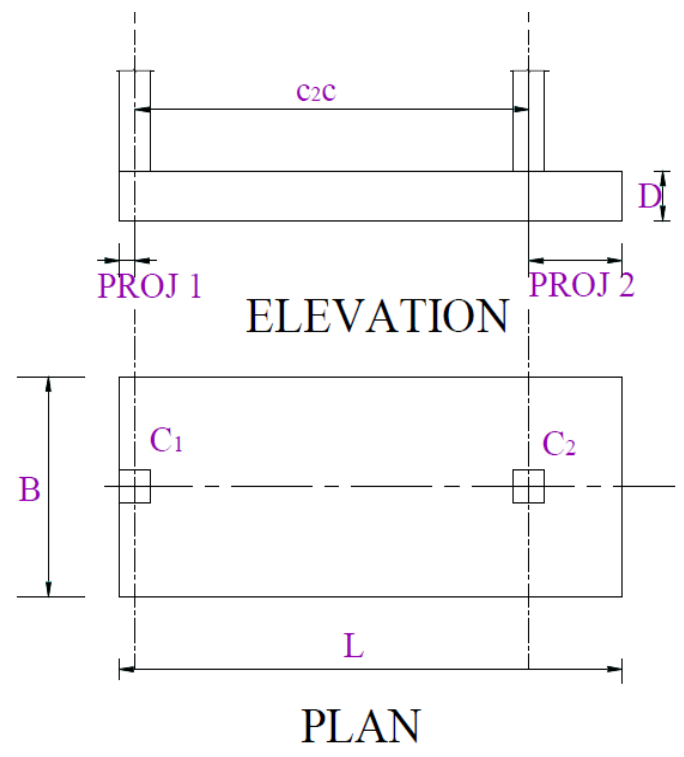

Fig -5: Plan and Elevation of combined Rectangular footing

Application of property of Rectangular combined footing to beam element:

1) Width of element $(w)=$ Width of Footing

2) Depth of element (d) = depth of footing

3) Material property of element $=$ material property of footing

4) Moment of Inertia of element (I) $=$ Moment of Inertia of footing

\subsection{Application of Finite Element Method for Combined Footing}

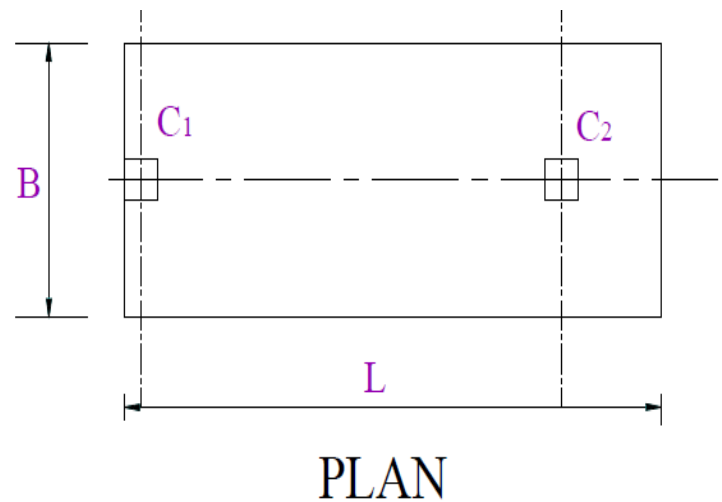

Fig -6: combined footing

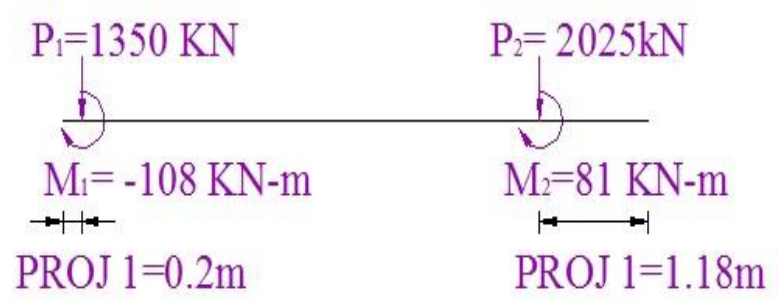

Fig -7: Free body of combined Rectangular footing

To analyze the footing by finite element method, initially discretize the given problem.

In the figure bellow (fig. 8 Discretizing the Problem) it is shown that the given footing is divided into three number of elements and four Nodal points, now according to Winkler's Model the soil is made-up of springs, therefore the springs are attached at each nodal points, which is having stiffness " $\mathrm{K}$ "

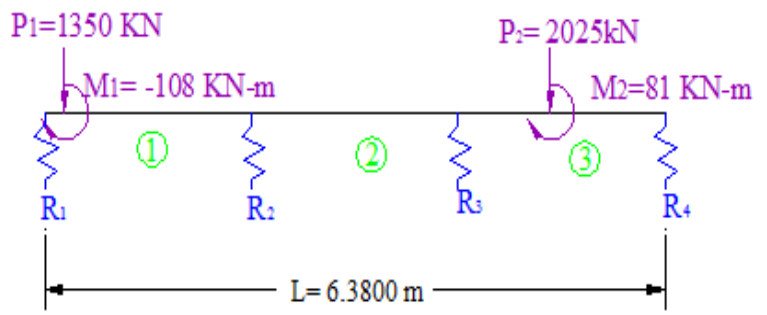

Fig -8: Discretizing the Problem

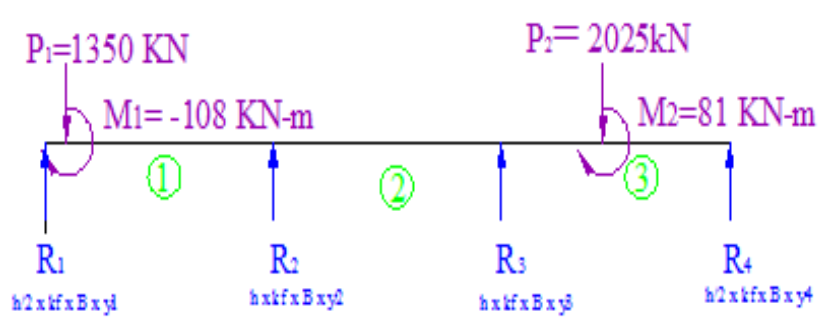

Fig -9: Spring Force

Now, the spring will give some reaction to the beam which is equal to product of effective area, Modulus of Subgrade reaction and Deflection at that point as given in fig. No. 9

Now, Find out the Stiffness matrix for each element that is local stiffness matrix then combine it and find out global stiffness matrix. 


$$
k=\frac{E \times I}{L^{3}}\left[\begin{array}{cccccccc}
12 & 6 L & -12 & 6 L & 0 & 0 & 0 & 0 \\
6 L & 4 L^{2} & -6 L & 2 L^{2} & 0 & 0 & 0 & 0 \\
-12 & -6 L & 24 & 0 & -12 & 6 L & 0 & 0 \\
6 L & 2 L^{2} & 0 & 8 L^{2} & -6 L & 2 L^{2} & 0 & 0 \\
0 & 0 & -12 & -6 L & 24 & 0 & -12 & 6 L \\
0 & 0 & 6 L & 2 L^{2} & 0 & 8 L^{2} & -6 L & 2 L^{2} \\
0 & 0 & 0 & 0 & -12 & -6 L & 12 & -6 L \\
0 & 0 & 0 & 0 & 6 L & 2 L^{2} & -6 L & 4 L^{2}
\end{array}\right]
$$

Fig -10: Global stiffness matrix

Scene the base is made-up of springs we have to add the stiffness contribution of those springs.

$$
[K]=\frac{E \times I}{L^{3}}\left[\begin{array}{cccccccc}
12+\left(k_{1} \times \frac{L^{3}}{E \times I}\right) & 6 L & -12 & 6 L & 0 & 0 & 0 & 0 \\
6 L & 4 L^{2} & -6 L & 2 L^{2} & 0 & 0 & 0 & 0 \\
-12 & -6 L & 24+\left(k_{2} \times \frac{L^{3}}{E \times I}\right) & 0 & -12 & 6 L & 0 & 0 \\
6 L & 2 L^{2} & 0 & 8 L^{2} & -6 L & 2 L^{2} & 0 & 0 \\
0 & 0 & -12 & -6 L & 24+\left(k_{3} \times \frac{L^{3}}{E \times I}\right) & 0 & -12 & 6 L \\
0 & 0 & 6 L & 2 L^{2} & 0 & 8 L^{2} & -6 L & 2 L^{2} \\
0 & 0 & 0 & 0 & -12 & -6 L & 12+\left(k_{4} \times \frac{L^{3}}{E \times I}\right) & -6 L \\
0 & 0 & 0 & 0 & 6 L & 2 L^{2} & -6 L & 4 L^{2}
\end{array}\right]
$$

Fig -11: Final stiffness matrix

It will give us the final stiffness matrix [K].

Finally, we know, $\quad \mathrm{F}=\mathrm{K} \times \delta$

$$
\delta=\mathrm{F} \times \mathrm{K}^{-1}
$$

We can get the deformation at various nodal points

Once the deformations are calculated, then base pressure and reaction offered by the springs can be calculate by following formula.

Base Pressure $=($ modulus of subgrade reaction $) \times($ Deflection at a point)

Reaction by spring $=($ Stiffness of Spring $) \times($ Deflection at that point)

A computer Program is written in MATLab for analysis of combined rectangular footing with moment on both column using Winkler's Model and Finite Element Method as it is suggested by Bhogade V M and Konapure C G [13]. MATLab is powerful software known for matrix calculation

\section{ANALYSIS OF COMBINED RECTANGULAR FOOTING BY VARIOUS METHODS:}

Following parametric investigation is carried out to study the Winkler's model and finite element method
1. The problem is analyzed by conventional method
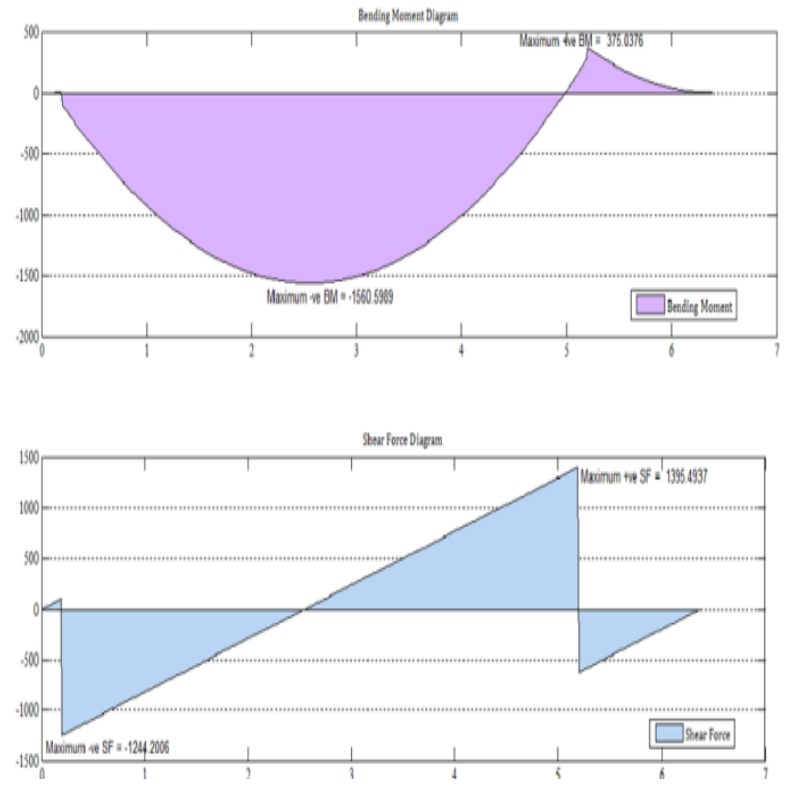

Fig -12: Shear Force and Bending moment along length of footing by conventional Analysis

2. The same problem is analyzed by Winkler's model and finite element method by varying following parameters.

a. Various number of element used

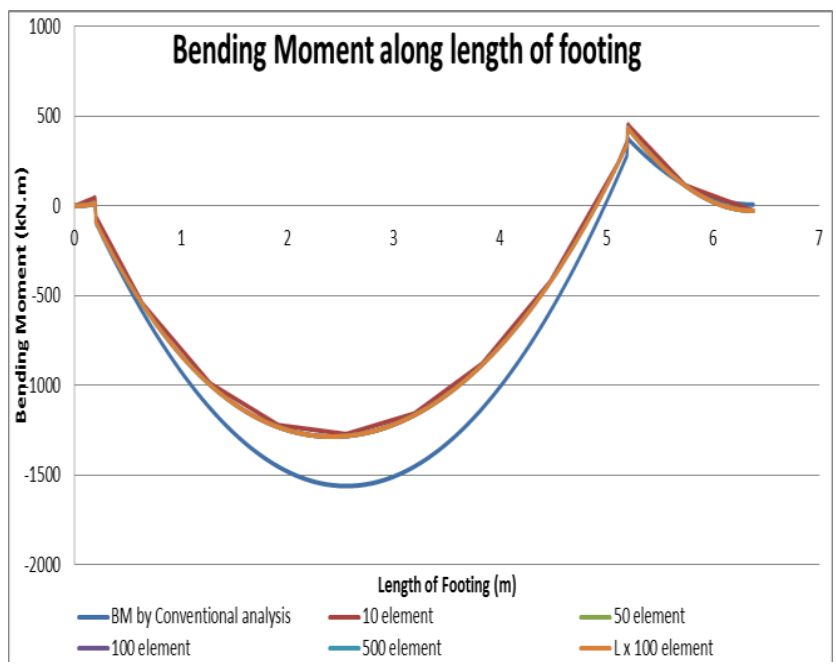

Fig -13: Bending Moment along length of footing 


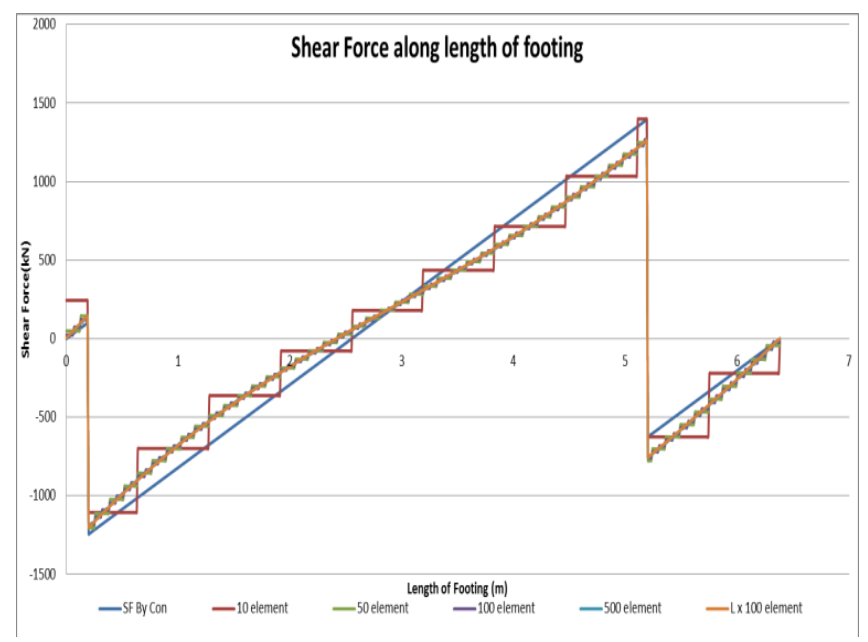

Fig -14: Shear Force Along length of footing

b. Variation in modulus of subgrade reaction

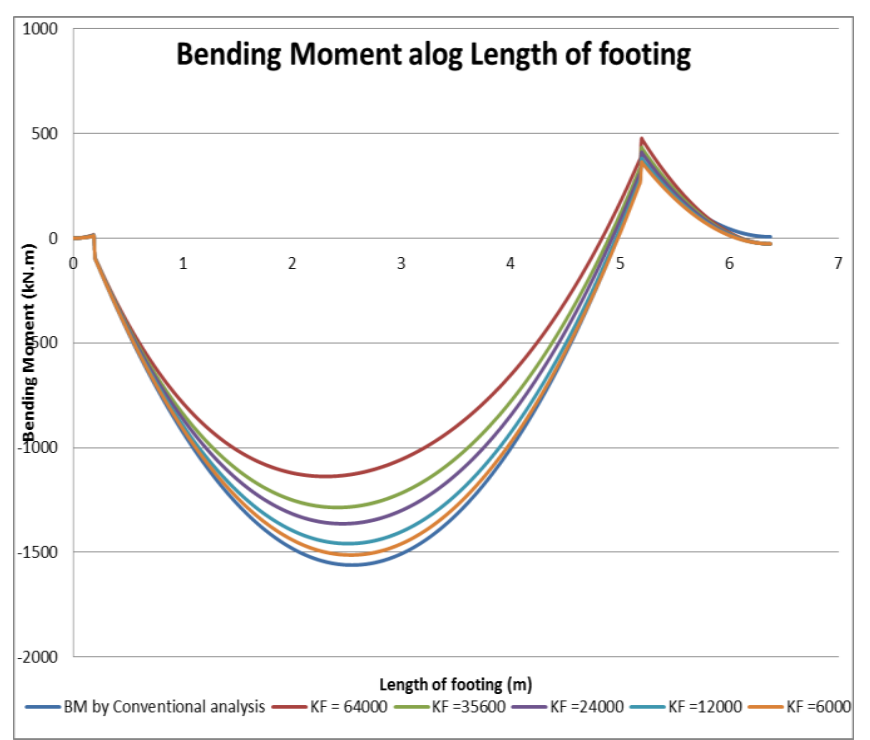

Fig -15: Bending Moment along length of footing

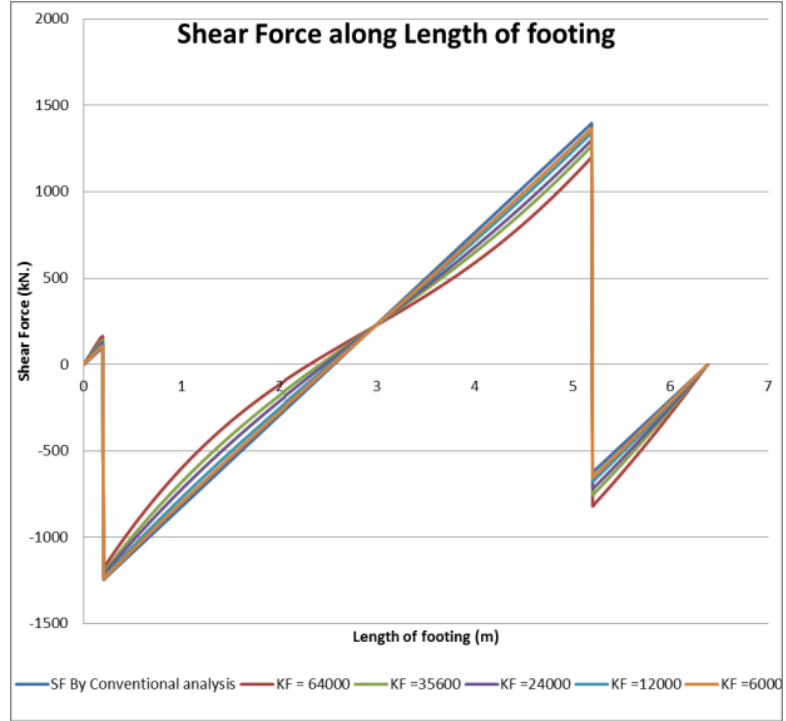

Fig -16: Shear Force Along length of footing

\section{CONCLUSIONS}

1. The number of elements shall be at least 50, however the variation in Bending moment, Shear force is not much smooth for above number of element.

2. As number of elements increased the values of Bending moment, Shear force are not much varying, But the diagrams are refined and smooth variation is observed.

3. As the modulus of subgrade reaction $\left(\mathrm{K}_{\mathrm{f}}\right)$ increases, maximum Bending moment decreases.

4. In conventional method the upward soil pressure is assumed to be uniform throughout the length of footing, the variation of Pressure distribution can be observed by applying Winkler's model and finite element method.

5. Future scope: the study can be extended for trapezoidal footing and Strap footing, with or without Moment on one or both column. Further the analysis can be carried out using plate element or the effect of variation in crosssection can be studied.

\section{REFERENCES}

[1] Bowels J.E., (1997) "Foundation Analysis And Design", 5th Ed., McGraw Hill Publishers.

[2] Daryl L. Logan ,"A First Course in the Finite Element Method", Fifth Edition.

[3] David V. Hutton (2004) "Fundamentals of Finite Element Analysis" McGraw Hill Publishers.

[4] Hetenyi M. (1946) "Beam on Elastic Foundation" University of Michigan Press. Ann Arbor, pp. 100106,255 pp.

[5] Swami Saran "Analysis and design of sub structure" (2009), second Ed., Oxford \& IBH.

[6] ACI (2002) "Suggested Analysis and Design Procedures for Combined Footings and Mats", ACI 
Committee 336Report, $21 \mathrm{pp}$. See also the "discussion" and "closure" in the ACI Structural Journal, vol. 86, no. 1, Jan-Feb, 1989, pp.111-16.

[7] David Roylance (2001) "Finite Element Analysis" Department of Materials Science and Engineering Massachusetts Institute of Technology Cambridge, MA 02139.

[8] Konapure C.G. \& Bhogade V.M. (Nov.2013) "Analysis of Combined Rectangular footing by Winkler's Model \& FEM “ Volume III Issues Of IJEIT Pg.No, 128 to 132.

[9] TeodoruIancu- Bogdan(2009) "A Computer Code for Analysing Beams on Elastic Foundations" the 7th Internat. Symp. "Computational Civil Engineering", CCE, "Gheorghe Asachi" Techn. Univ., Faculty of Civil Engng., Jassy, 2009.

[10] TeodoruIancu- Bogdan,(2009)"The Beams on Elastic Foundation, the Simplified Continuum Approach"" the 7th Internat. Symp. "Computational Civil Engineering", CCE, "Gheorghe Asachi" Techn. Univ., Faculty of Civil Engng., Jassy, 2009.

[11] MAT Lab, A Powerful software to analyze the matrix operations.

[12] http://www.enggpedia.com/civil-engineeringencyclopedia/295-soil-mechanics-geotechnicalfoundation-engg/1710-foundations-definition-types-apurposes-of-foundations.

[13] http://www.raisedfloorlivingpro.com/footings.shtml

[14] http://www.publishing.uwa.edu.au/research/1994/civilengineering.asp.

[15] http://sydney.edu.au/engineering/civil/cgr/research.sht $\mathrm{ml}$.

\section{BIOGRAPHIES}

Prof. Vivek Meghraj Bhogade, Assistant Professor, Department of civil Engineering, A. G. Patil Institute of Technology, Solapur. Life member of Indian society of Technical Education

Mr. Laxmilant S. Arkal, Student of final year Civil Engineering

Mr. Rushikesh V. Bandgar, Student of final year Civil Engineering

Mr. Fahim A. S. Kalekhan, Student of final year Civil Engineering 